\title{
ROLEZINHO NO HEMEPAR: A PUBLICIDADE SOCIAL EM \\ FAVOR DA DOAÇÃO DE SANGUE
}

\author{
Víctor Murilo Carbornar ${ }^{1}$ \\ Eliane Basilio de Oliveira ${ }^{2}$
}

\section{Resumo}

Este texto apresenta um estudo de caso do vídeo "Rolezinho no Hemepar", lançado com objetivo de aumentar as doações de sangue em Curitiba. Para isso, foi realizado um estudo sobre as técnicas utilizadas pela publicidade na construção do sentido do conteúdo da mensagem do vídeo, levando em conta elementos como imagens, intertextualidade e trilha sonora. Ao final da análise, percebemos a importância do papel da publicidade em campanhas como essa.

Palavras-chave: Publicidade, mobilização social, redes sociais, doação de sangue.

\section{Abstract}

The aim of this text is to present a case study of "Rolezinho no Hemepar", a video delivered in order to increase blood donation in Curitiba. To do so, we carried out a study about advertising techniques used in building sense to the video message, such as images, intertextuality and soundtrack. At the end of this analysis, we notice the importance of advertising in campaigns like that.

Keywords: Advertising, social mobilization, social network, blood donation.

\section{Introdução}

Dados do Ministério da Saúde (2011) apontam que o número de doadores de sangue não é suficiente para atender à demanda no país. Apesar da coleta estar dentro dos parâmetros internacionais, o aumento da procura requer mudanças. Isso porque as atuais 3,5 milhões de bolsas coletadas não são suficientes; o ideal é chegar a 5,7 milhões por ano. E campanhas de divulgação podem ser ferramentas importantes para a mudança de hábitos.

Diante desta realidade, este artigo busca compreender quais são os elementos discursivos na construção de sentido de uma peça de propaganda de doação de sangue. Queremos identificar os conteúdos utilizados na construção do sentido no vídeo da campanha do "Rolezinho no Hemepar", em Curitiba, em fevereiro de 2014, e os resultados alcançados com a campanha no Facebook. Este trabalho foi organizado em duas partes: na primeira, foram

\footnotetext{
1 Aluno do curso de graduação em Comunicação Social: Publicidade e Propaganda do Centro Universitário Curitiba (UniCuritiba).

${ }^{2}$ Socióloga (PUC-PR), mestre em Educação (UFPR), professora nos cursos de Comunicação do UniCuritiba e da Universidade Positivo. Orientadora do trabalho.
} 
discutidos os conceitos de publicidade e propaganda, propaganda social, a construção de sentido e redes sociais. Na segunda, foi feita análise de vídeo sobre doação de sangue.

\section{Conceitos iniciais}

Na sociedade contemporânea, os conceitos de publicidade e propaganda são utilizados indistintamente. Apesar disso, possuem diferenças. A publicidade e a propaganda modernas refletem o desenvolvimento industrial após o século XIX, com a formação do mercado de massa. Suas técnicas foram aperfeiçoadas para atender as novas necessidades do mundo capitalista, apesar de práticas semelhantes já existirem em outras épocas.

Segundo Eloá Muniz (2014), uma forma rudimentar de publicidade já estava presente na Antiguidade, realizada oralmente pelos comerciantes, prática que se estendeu à Idade Média. Em 1440, o desenvolvimento da imprensa proporcionou o avanço da comunicação escrita e da publicidade. A pesquisadora destaca que a palavra publicidade passou a ser utilizada para designar o ato de divulgar, de tornar público, informar. Tem origem no latim publicus (público), dando origem ao termo publicité em língua francesa.

O avanço industrial do século XIX transformou o significado da publicidade como uma ferramenta de informação para uma ação comercial. A publicidade designa "qualquer forma de divulgação de produtos ou serviços, através de anúncios geralmente pagos e veiculados sob a responsabilidade de um anunciante identificado, com objetivos de interesse comercial" (MUNIZ, 2014, p.3). A ampliação da concorrência incentivou o surgimento de novas técnicas na publicidade, tornando-a mais persuasiva, diminuindo o sentido informativo inicial.

O termo propaganda vem do latim propagare (propagar, difundir, multiplicar). "Uma expressão de opinião por parte ou ação de indivíduo ou grupos, deliberadamente destinada a influenciar opiniões ou ações de outros indivíduos ou grupos relativamente a fins predeterminados" (MUNIZ, 2014, p.5). A autora ainda destaca que o termo foi instituído no século XVII pela Igreja Católica, com a finalidade de difundir a religião. Como aconteceu com a publicidade, depois da Revolução Industrial, houve a propagação dessa atividade nos mais diversos tipos de negócios comerciais e industriais. Mas foi a partir da criação de meios como o rádio, o cinema, a fotografia e a TV que a propaganda pôde ser implantada de forma abrangente.

No Brasil, publicidade e propaganda são conceituadas indistintamente. Segundo Monteiro (2014), essa confusão está relacionada com alguns erros de traduções do termo "advertising", utilizado nos Estados Unidos para definir a comunicação comercial, traduzido 
no Brasil como propaganda. O autor destaca que "a comunicação comercial é chamada pelos americanos de advertising, pelos franceses de publicité, pelos espanhóis de publicidad, pelos italianos de publicità e todos esses entendem o termo propaganda como comunicação política, cívica ou religiosa."

De acordo com as definições, podemos observar que a publicidade é uma ação voltada mais para o desenvolvimento da venda de produtos e serviços, a partir da persuasão dos consumidores para a obtenção de lucro, ou seja, está ligada aos interesses comerciais. Já a propaganda está voltada à propagação daquilo que precisa ser divulgado para o público-alvo, possui um caráter ideológico e tem como objetivo fazer adeptos, seguidores e mudar comportamentos e opiniões, no campo político, cívico e religioso.

Para analisar o objeto desta pesquisa será adotada a diferenciação entre publicidade e propaganda e utilizado o conceito de propaganda social, ou seja, uma ação realizada por uma instituição que busca sensibilizar e mobilizar os indivíduos.

\section{Propaganda social}

Morais e Felizola salientam que, seja no âmbito profissional, comercial, institucional ou social, a propaganda tem papel decisivo para a aceitação de algum serviço ou produto. Segundo eles, para que a propaganda alcance o objetivo pretendido "ela precisa atender alguns princípios básicos como a criatividade, a emoção e interesse, pertinência e compreensão" (MORAIS; FELIZOLA, 2011, p.3-4). Os autores ainda ressaltam a importância que a propaganda possui no cotidiano, pois é por meio dela que podemos conhecer melhor aquilo que o mundo nos apresenta, e, dessa forma, decidimos pelo que nos convém.

Os pesquisadores reforçam a importância da propaganda não só como divulgação de marcas ou empresas, mas como uma ação voltada para o interesse público, como campanhas de doação de sangue, por exemplo. O conceito de campanhas de interesse público aponta:

\footnotetext{
Comunicação de Interesse Público é toda ação de comunicação que tem como objetivo primordial levar uma informação à população que traga resultados concretos para se viver e entender o mundo melhor. Na Comunicação de Interesse Público, o beneficiário direto e primordial da ação de comunicação sempre será a sociedade e o cidadão. Sua missão, portanto, se traduz num esforço para difundir, influenciar, criar ou mudar comportamentos individuais ou coletivos em prol do interesse geral (MORAIS; FELIZOLA, 2011, p.4).
}

A comunicação de interesse público visa conscientizar o público e mostrar que o objetivo maior é o bem comum, de toda a sociedade, portanto esse conceito dialoga com a 
definição de propaganda social, que apresenta uma preocupação com as causas sociais de interesses público.

\section{A construção do sentido}

Apesar da distinção entre publicidade e propaganda, as técnicas utilizadas para a construção do texto são as mesmas. O discurso publicitário é realizado a partir da observação e análise da realidade social de seu público-alvo, que constituirá a base para a construção comunicacional, para estabelecer um conteúdo sobre o qual será produzido o sentido através da emissão do discurso publicitário. Devem ser considerados na elaboração deste processo os meios em que será emitido o discurso publicitário, a linguagem específica para cada veículo.

Para Carvalho, a discussão sobre o texto publicitário sempre remete aos conceitos de persuasão e manipulação, assim, "quando se analisa a linguagem publicitária quase sempre se fala em manipulação" (2001, p.9). Na verdade, o que diferencia a linguagem publicitária da linguagem cotidiana são os métodos utilizados para o convencimento do público-alvo. Segundo a autora, em ambos os casos o objetivo é informar, mas, no caso da linguagem publicitária, utilizam-se artifícios para persuadir e convencer.

Para apontar a força de persuasão que a linguagem publicitária exerce sobre o públicoalvo, a autora destaca que, "com o uso de simples palavras, a publicidade pode transformar em relógio em uma joia, um carro em símbolo de prestígio e um pântano em paraíso tropical” (CARVALHO, 2001, p.18).

Segundo Muniz (2005, p.7), “a comunicação publicitária, portanto, se realiza através de um processo que, em primeiro lugar, analisa a informação captada no mercado, filtrando, selecionando e, posteriormente, transformando em mensagem.” Para isso, é necessária uma pesquisa minuciosa a respeito do público que se pretende atingir, que servirá de impulso para a campanha a ser elaborada, e, consequentemente, a aceitação ou a recusa do serviço ou produto, que venha a ser divulgado.

Muniz (2005, p. 6-7) ainda destaca as estratégias utilizadas nas criações publicitárias, como: a mensagem deve ser condizente com o meio de comunicação no qual ela será transmitida; é importante saber valores de produtos ou serviços atribuídos pelos consumidores; no caso de recusa do produto ou serviço, é melhor que se faça a retirada dos mesmos do mercado; conhecer características do consumidor em potencial. Desta forma, cabe ao publicitário recorrer a procedimentos variados e eficazes, utilizando-se de tais estratégias, de 
forma a fazer com que seus receptores assimilem a mensagem proposta e sejam influenciados por ela.

Outro recurso bastante utilizado na construção do sentido da mensagem publicitária é a intertextualidade, utilizada na construção do texto publicitário, que explora uma pluralidade de sentidos, visando a persuasão do receptor. A intertextualidade se materializa no uso de textos verbais, visuais, que constituem uma determinada esfera cultural. São exemplos desta técnica o uso na construção da mensagem publicitária a estilização, alusão, citação ou paródia (KNOLL, 2014). As estratégias de persuasão e intertextualidade são importantes na construção do sentido na mensagem da propaganda social.

A eficiência da propaganda social está ligada à capacidade de observação das características culturais, sociais, simbólicas que formam a realidade do consumidor que se deseja atingir. Para que a mensagem da propaganda possa alcançar um grande número de pessoas é importante também observar quais os melhores meios de publicação das campanhas de comunicação. Com a ampliação das tecnologias de informação, a publicidade e a propaganda estão cada vez mais utilizando as redes sociais como meio de divulgação de suas mensagens.

\section{Publicidade e novas mídias}

Depois da criação de todos os meios de comunicação que impulsionaram o sistema publicitário, surgiu a internet, mais uma ponte com o público-alvo. Segundo o Ibope Media de 2013, “em 2008, o Brasil atingiu a meta de 10 milhões de conexões”. Atualmente, o número de usuários da internet estipulado no país está na faixa dos "105 milhões", "sendo o Brasil o $5^{\circ}$ país mais conectado." Em contrapartida, a mesma pesquisa constatou que a desigualdade social prevalece e também se reflete no acesso à internet: “[...] dos $10 \%$ dos pobres, apenas $0,6 \%$ tem acesso à internet; entre os $10 \%$ mais ricos esse número é de 56,3\%" (IBOPE MEDIA, 2014).

Apesar do acesso à internet ainda não ser uma realidade para todos os brasileiros, o crescimento do número de usuários está se ampliando a cada dia, principalmente com o desenvolvimento das redes sociais virtuais. O crescimento do acesso à internet e suas redes sociais, principalmente Facebook e Youtube, fortalece essa relação, pois são ferramentas que dialogam das mais diversas formas, engendrando maneiras diferenciadas de comunicação, que permitem uma maior participação do público virtual, em seus projetos e ações, e uma maior interação entre os usuários e seus contatos (RECUERO, 2014).

Segundo Carvalho (2014), as transformações na comunicação desencadeadas pelo avanço da internet e do uso das redes sociais estão se refletindo também nos "departamentos de 
marketing das organizações e nas agências de publicidade", pois esses setores estão mudando seus investimentos, ações e formas de dialogar com os consumidores. Antes da era digital, os anúncios eram criados tendo como base alguns aspectos físicos, econômicos e culturais do público que se pretendia alcançar. A publicidade e a propaganda, fazendo uso dos meios de comunicação existentes na época, faziam seus anúncios e divulgações estando cientes das necessidades dos consumidores e da construção de sentido de melhor persuasão, fato que muitas vezes garantia o sucesso de qualquer campanha veiculada (CARVALHO, 2014, p.3).

Segundo o autor, com o surgimento da geração $\mathrm{Y}$, o mundo publicitário se viu na incumbência de transformar suas ações para suprir as necessidades dessa nova geração, cheia de exigências e com sede de novidades. Para Carvalho, na era da internet e das redes sociais, o jovem que vive conectado está a todo momento sendo bombardeado por inúmeras novidades. A publicidade se torna mais acessível, e comprar e vender ficou bem mais fácil. Hoje a concorrência atravessa fronteiras, e para que todos ocupem lugar no mercado a publicidade precisa inovar e reformular seus conceitos. Para tanto, são necessárias pesquisas mais amplas, que consigam captar o perfil desse novo consumidor, mais exigente e participativo.

O grande número de usuários das redes sociais principalmente do Facebook está também transformando essas ferramentas em um instrumento de marketing. Cada vez mais as empresas utilizam as redes sociais na divulgação de produtos, serviços e para o diálogo com os consumidores. As empresas estão se engajando nas redes sociais, e o Facebook está fortalecendo essa aliança por meio do serviço de marketing, na tentativa de transformar "fãs em clientes" (PORTO, 2014, p.100-101).

Com o crescimento contínuo do uso das redes sociais no Brasil, o Ministério da Saúde também passou a utilizar este espaço para discutir os problemas de saúde e para o desenvolvimento de campanhas comunicacionais, visando a mudança de comportamentos e a mobilização dos indivíduos.

\section{Redes sociais e promoção da saúde}

A internet, com todo seu aparato de comunicação, também está inserida na área da saúde, atuando como um difusor de ideias e opiniões a respeito desse assunto. No tocante à saúde, muitas são as dúvidas e opiniões que surgem ao longo do tempo. E o uso da internet como suporte de ajuda nesses casos é primordial, pois vem sanar problemas de ordem social. “A importância, para a Saúde, da Informação e da Comunicação também é consenso entre estudiosos e ativistas brasileiros desde a $8^{\text {a }}$ Conferência Nacional de Saúde, que em 1986 
esboçava a criação do Sistema Único de Saúde (SUS) (Brasil, 1986)” (SOBREIRA, 2014, p.10). $\mathrm{O}$ autor ainda destaca que com a criação da internet essa comunicação tornou-se mais viável e acessível.

Um exemplo são as campanhas de caráter social. Com o intuito de melhorar o sistema de doação de sangue, o Ministério Público criou uma página no Facebook, permitindo que futuros doadores possam se cadastrar através da rede social, possibilitando uma maior divulgação, tendo em vista a corrente que se forma com os compartilhamentos que são passados adiante e que podem multiplicar o número de doadores (MINISTÉRIO DA SAÚDE, 2014).

\section{Análise da campanha}

O vídeo intitulado "Campanha do Rolezinho no Hemepar - Doação de Sangue e Medula Óssea"3 foi produzido em 2014, para o canal da rede social Youtube Como se Fala em Curitiba, com a direção de Rafael Micheletto, com a duração de 4 minutos e 4 segundos. O principal tema abordado é a necessidade de doação de sangue em Curitiba. Nessa campanha, de fevereiro a maio de 2014, o canal Youtube teve 4.135 visualizações e o Facebook 201 curtidas.

O diferencial desse tipo de campanha é que podemos mensurar a quantidade de pessoas que foram impactadas e efetivaram o ato de doar sangue, por meio do evento criado no Facebook, em que o público participante pode confirmar sua presença no evento. Já em outras campanhas, como as realizadas pela Fundação Pró-Sangue ${ }^{4}$, onde são utilizados banners, folhetos, folders, não é possível dimensionar exatamente a quantidade de doadores que tomaram tal atitude.

Para analisar o vídeo, foi utilizada a metodologia de análise de conteúdo. De acordo com Bardin (2009), trata-se de um conjunto de técnicas, procedimentos sistemáticos e objetivos utilizados para a descrição e análise do conteúdo das mensagens. Essa metodologia busca descrever e entender o sentido do texto. Para aplicá-la, o pesquisador deve desenvolver categorias de análise. "O processo de categorização pode ser definido como uma operação de classificação de elementos constitutivos de um conjunto por diferenciação e seguidamente, por reagrupamento segundo o gênero" (CAMPOS, 2014, p.613).

Campos (2014) ainda destaca que as categorias podem ser caracterizadas "como grandes enunciados", formando um conjunto de "temas", que venham a desmembrar a análise do

\footnotetext{
${ }^{3}$ Disponível em: <http://www.youtube.com/watch?v=2sW6j6tIIK4> . Acesso em: 24 mar. 2014.

4 FUNDAÇÃ O pró-sangue: hemocentro de São Paulo. Disponível em: <http://www.prosangue.sp.gov.br/comunicacao/Default.aspx >. Acesso em: 04 mai. 2014.
} 
conteúdo, produzindo significações diferenciadas, com a finalidade de criar novas ideias, abrindo portas para o conhecimento, "proporcionando uma visão diferenciada sobre os temas propostos". Para a realização da análise de conteúdo do vídeo foram construídas as seguintes categorias: Imagens (personagens; ambientação no Hemepar; a ação); intertextualidade; linguagem de persuasão; trilha sonora.

\section{Imagens}

Ao estudar o desenvolvimento do cinema e do documentário como ferramentas de representação e construção da realidade, Nichols $(2005$, p.25) afirmou que "todo filme é um documentário. Mesmo a mais extravagante das ficções evidencia a cultura que a produziu, e reproduz a aparência das pessoas que fazem parte dela". Partindo desta afirmação, é possível observar que a construção do vídeo utiliza algumas linguagens do cinema ficcional e também das técnicas do documentário, pois representam uma maneira de ver e imaginar a realidade.

Ao analisar as diferenças entre o cinema ficcional e o documental, Nichols (2005) construiu o conceito de "voz" e de "modos de representação" no cinema documental. O objetivo do autor é compreender o posicionamento ético e os recursos de representação utilizados na produção do documentário para representar a realidade e se diferenciar do filme ficcional.

O vídeo "Rolezinho no Hemepar" é uma propaganda social que busca modificar um comportamento, ou seja, convencer o cidadão sobre a importância da doação de sangue. Este vídeo não se enquadra na definição de documentário, mas utiliza um recurso de representação definido por Nichols, o modo de representação performático, centrado na primeira pessoa, que “[...] sobredetermina a reflexividade-participativa da enunciação, constituindo-se através da subjetividade pessoal da performance, do próprio encenar da representação pelo sujeito em frente da câmera" (NICHOLS, 2005, p.138).

O filme inicia com a apresentação dos personagens, Eliane Aparecida dos Santos, de 31 anos, Renata Petisco (24) e Felipe Barbosa Neto (30). Essas três pessoas têm problemas relacionados à questão sanguínea e relatam como foi a descoberta da doença, as dificuldades de se conseguir doadores e, sobretudo, do bem que o ato de doar sangue pode trazer à vida delas. A fala dos três personagens é intercalada com mensagens como: "O Brasil necessita diariamente de 5,5 mil bolsas de sangue", "A cada doação é possível salvar 3 vidas", e "Para mostrar a importância da doação de sangue, dois curitibanos criaram uma mobilização chamada Rolezinho no Hemepar.” 
A estratégia utilizada na construção e apresentação dos personagens se enquadra na definição do "modo de representação performático", de Nichols, pois explora a subjetividade, a performance, a história pessoal do sujeito que está na frente da câmera. A história individual é mostrada como parte da realidade social, reforçada pelos dados que são inseridos entre os depoimentos dos personagens.

Outro recurso utilizado para a construção do discurso de verdade são várias reportagens de mídia espontânea sobre o evento, entre elas, muitos sites com reportagens, a página do Rolezinho no Facebook, e essas imagens passam em conjunto com as narrações de apresentadores de televisão, como o jornalista e apresentador do jornal da RPCTV Sandro Dalpícolo, que também geraram mídia para esse evento. O vídeo utiliza o recurso da intertextualidade com o jornalismo para convencer o indivíduo a se tornar um doador de sangue.

\section{Ambientação}

O vídeo reforça a importância da doação de sangue por meio de relatos dos três personagens, Eliane, Renata e Felipe. Enquanto eles relatam seus testemunhos, aparecem cenas de doadores e bolsas de sangue. O enquadramento das câmeras na filmagem geralmente é feito em close. A parte externa do Hemepar foi o ambiente utilizado para o depoimento de Eliane. $\mathrm{Na}$ parte interna, na sala onde são realizadas as doações de sangue, ocorreu o depoimento de Renata. Também no ambiente interno, porém na sala de espera do Hemepar, aconteceu o relato de Felipe.

\section{A ação}

O vídeo mostra várias pessoas, entre crianças e adultos, segurando placas com as frases: "Esse Rolezinho eu curto" e "Doe sangue e salve vidas". Renata também fala sobre a importância da doação de sangue e a diferença que faz para quem recebe. Eliane e Felipe falam de como são gratos pelas doações. Esse trecho mostra também algumas peças de propagandas sobre doação de sangue e uma sobre doação de medula óssea. Entre um depoimento e outro aparecem pessoas doando sangue.

\section{Intertextualidade}

A intertextualidade está presente em todo o contexto que norteia a apresentação do vídeo, por meio de recursos audiovisuais utilizados para maximizar a produção de efeitos e imagens, objetivando uma melhor assimilação da mensagem divulgada. Por exemplo, a 
inserção de reportagens jornalísticas no vídeo busca construir uma relação de verdade com o espectador.

Outra marca da intertextualidade com o jornalismo presente no vídeo está na associação, como o próprio título sugere, com as notícias jornalísticas veiculadas em janeiro de 2014 sobre os rolezinhos nos shoppings e também veiculados nos jornais das grandes emissoras de televisão, em que muitas pessoas, em geral jovens, se reuniam para fazer uma grande correria dentro dos estabelecimentos comerciais, evento esse, que apesar de muito polêmico, foi utilizado para se identificar com o jovem do "rolezinho" e mobilizá-lo para outro rolezinho: o do Hemepar.

\section{Linguagem de persuasão}

Como em todo processo publicitário, as campanhas para doação de sangue são idealizadas para persuadir seus receptores. Mas, nesse caso, os elementos de persuasão precisam ter uma conotação própria, com o intuito de educar e trabalhar na mudança de atitude de um determinado grupo, que, muitas vezes, devido a "crenças" e costumes, não se abre para o novo, e por isso precisa ser moldado e trabalhado por meio da comunicação persuasiva.

A linguagem de persuasão apresentada no vídeo apresenta algumas características. $\mathrm{Na}$ questão da exploração dos sentimentos, a utilização dos relatos provindos de pessoas que necessitam da doação de sangue para sobreviver, os quais são os protagonistas dessa história, é um exemplo desse tipo de estratégia, que leva o indivíduo a pensar na situação do outro e sentir vontade de participar na resolução do problema. A simplificação também faz parte da apresentação do vídeo. A repetição de temas e ideias de formas orquestradas é uma estratégia que, de certa forma, faz parte do vídeo e harmoniza a história, quando as ideias se repetem, dando ênfase à mensagem dirigida ao público. E, por fim, o apoio às atitudes preexistentes é fator determinante na realização do vídeo, sendo talvez essa a principal estratégia, pois o objetivo principal do vídeo é fortalecer os vínculos com aqueles que já são doadores e servir de incentivo para aqueles que porventura ainda não se convenceram da importância dessa ação transformadora.

\section{Trilha Sonora}

Cecim (2011) aponta a importância da inserção da música no processo de criação da publicidade audiovisual, o que pode ser fator determinante no processo de persuasão. Essa estratégia de persuasão pode ser percebida na composição do vídeo. A trilha sonora apresentada 
no vídeo é composta por duas músicas instrumentais. A princípio, a primeira música é entoada num tom melancólico, como forma de envolver de imediato o receptor, sensibilizando-o para a situação apresentada, quando os participantes começam a relatar suas histórias. Na continuação, depois da comoção, eis que surge a segunda música com um tom mais ativo, configurando uma ambientação mais alegre, demonstrando que o problema tem solução, desde que todos se conscientizem e se mobilizem para transformar a realidade.

\section{Considerações finais}

A partir das discussões teóricas abordadas na pesquisa, é possível perceber a importância da publicidade e da propaganda social em campanhas voltadas para a questão social. As técnicas de persuasão impulsionam esse tipo de campanha, pois são peças importantes para transformar uma situação.

A utilização de redes sociais pela propaganda na área da saúde é fator relevante na pesquisa, pois devido à grande quantidade de usuários a internet pode ser considerada uma ferramenta indispensável na conquista de novos adeptos. O Ministério da Saúde tem investido na divulgação de sites relacionados à área da saúde, voltados para o bem-estar. E a propaganda tem se empenhado na obtenção de resultados positivos, fazendo uso de estratégias que enfatizam a importância de campanhas desse porte. Realmente, os dados resultantes desse tipo de campanha são positivos e relevantes.

Analisando o vídeo, podemos perceber, de forma mais incisiva, as técnicas utilizadas na campanha para convencer o público-alvo, como a persuasão e o intertexto, ferramentas importantes que de forma coerente e bem utilizadas podem tornar-se fatores decisivos na concretização de um resultado final positivo em uma campanha publicitária.

As músicas utilizadas, os depoimentos de pessoas que necessitam da doação de sangue, o cenário utilizado ajudam a enfatizar a gravidade do problema apresentado pela campanha em questão e como se pode solucioná-lo, orientando e informando sobre as atitudes que devem ser transformadas no meio social para sanar o problema.

(Artigo enviado em 14/06/2014, aprovado em 25/07/2014) 


\section{Referências}

ACESSO à Internet e posse de telefone móvel celular para uso pessoal 2011. IBGE. Disponível em: 〈ftp://ftp.ibge.gov.br/Acesso_a_internet_e_posse_celular/2011/PNAD_Inter_2011.pdf >. Acesso em: 24 abr.2014.

BARDIN, L. Análise de Conteúdo. Lisboa: Edições 70, 2009.

BRASIL, Ministério da Saúde. Relatório final da $8^{a}$ Conferência Nacional de Saúde, Brasília, 1986. Disponível em: <http://infocomsaude.wordpress.com/2011/08/11/relatorio-final-da8\%C2\%AA-conferencia-nacional-de-saude/>. Acesso em: 26 abr.2014.

CAMPANHA do rolezinho no hemepar. Direção: Raphael Micheletto. Curitiba, 2014. Youtube (4 min). Disponível em:< http://www.youtube.com/watch?v=2sW6j6tIIK4 >. Acesso em: 24 mar. 2014.

CAMPOS, Claudinei José Gomes. Método de análise de conteúdo: ferramenta para a análise de dados qualitativos no campo da saúde. SCIELO. Disponível em: <http://www.scielo.br/pdf/reben/v57n5/a19v57n5.pdf>. Acesso em: 14 mai.2014.

CARVALHO, João Henrique Dourado de. A publicidade nas redes sociais e a geração $Y$, a emergência de novas formas de comunicação publicitária. Disponível em: <http://www.ipea.gov.br/panam/pdf/GT2_Art8_Joao.pdf〉. Acesso em: 27 abr.2014.

CARVALHO, Marcia. $O$ documentário e a prática jornalística. Disponível em: <http://www2.eca.usp.br/pjbr/arquivos/ensaios7_d.htm>. Acesso em 16 mai.2014.

CARVALHO, Nelly de. Publicidade: A linguagem da sedução. São Paulo: Ática,1996.

CECIM, Samuel Krentkoski. Trilha sonora: o poder de persuasão da música em comerciais de televisão do anunciante de automóveis Renault. Disponível em: <http://lapecpp.files.wordpress.com/2011/05/samuel-i-cecim-trilha-sonora-o-poder-de-

persuasc3a3o-da-mc3basica-em-comerciais-de-televisc3a3o-do-anunciante-deautomc3b3veis-renault.pdf $>$. Acesso em 24 mai.2014.

KNOLL, Graziela Frainer. Intertextualidade: O anúncio publicitário como produto de relações dialógicas.

<http://www.reitoria.uri.br/ vivencias/Numero_010/artigos/artigos_vivencias_10/113.htm>.

Acesso em 24 mai.2014.

MINISTERIO da Saúde. As Cartas da Promoção da Saúde \pm Projeto Promoção da Saúde. Brasília, 2002. Disponível em: <http://bvsms.saude.gov.br/bvs/publicacoes/cartas_promocao.pdf >. Acesso em: 26 abr.2014.

MINISTÉRIO da saúde busca doadores nas redes sócias. Estadão. Disponível em: $\quad\langle$ http://www.estadao.com.br/noticias/vidae,ministerio-da-saude-busca-doadores-desangue-nas-redes-sociais, 802850,0.htm>. Acesso em: 17 mai.2014.

MONTEIRO, Dennys. A diferença entre publicidade e propaganda. Disponível em: $<$ http://rg9.org/propagare.php>. Acesso em: 22 mai.2014.

MORAIS, Mateus de Souza; FELIZOLA, Matheus Pereira Mattos. A Propaganda como Semeadora de Informações e Ideias por um Mundo Melhor e a Análise dos Cases "Razões para Acreditar", da Coca-Cola e "Embrace Life". INTERCOM, 2011. Disponível em: <http://www.intercom.org.br/sis/2011/resumos/R6-0639-1.pdf>. Acesso em: 05 mai.2014. 
MUNIZ, Eloá. Discurso publicitário e produção de sentido. INTERCOM. Disponível em: $\langle$ http://www.intercom.org.br/papers/nacionais/2005/resumos/R1988-1.pdf $>$. Acesso em: 05 mai.2014.

Publicidade e propaganda: Origens históricas. Disponível em: <http://eloamuniz.com.br/arquivos/1188171156.pdf>. Acesso em: 20 mai.2014.

NICHOLS, Bill. Introdução ao Documentário. São Paulo: Papirus, 2005.

NÚMERO de pessoas com acesso à internet passa de 100 milhões. IBOPE. Disponível em: $<$ http://www.ibope.com.br/pt-br/noticias/paginas/numero-de-pessoas-com-acesso-a-internetpassa-de-100-milhoes.aspx>. Acesso em: 24 abr.2014.

PORTO, Camila. Marketing Digital, mídias sociais e Facebook. Disponível em:

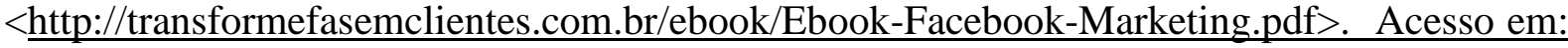
26 abr.2014.

RECUERO, Raquel. Redes Sociais na Internet, Difusão de Informação e Jornalismo. Disponível em: 〈http://www.raquelrecuero.com/artigos/artigoredesjornalismorecuero.pdf>. Acesso em 28 abr.2014

SOBREIRA, Isabel Levy. Práticas de comunicação e saúde no ciberespaço, uma análise a partir da campanha nacional de combate à dengue, 2011/2012. Disponível em: <http://www.arca.fiocruz.br/bitstream/icict/7132/1/Isabel\%20Levy.pdf >.Acesso em: 26 abr.2014. 